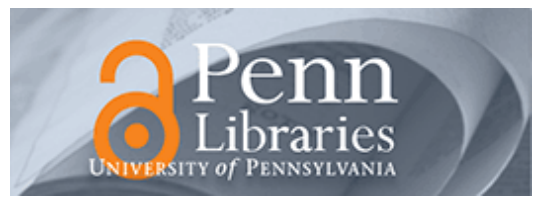

University of Pennsylvania

ScholarlyCommons

Marketing Papers

Wharton Faculty Research

8-1995

\title{
Market Share and Distribution: A Generalization, a Speculation, and Some Implications
}

David J. Reibstein

University of Pennsylvania

Paul W. Farris

Follow this and additional works at: https://repository.upenn.edu/marketing_papers

Part of the Business Administration, Management, and Operations Commons, Business Analytics Commons, Business and Corporate Communications Commons, Business Intelligence Commons, Management Sciences and Quantitative Methods Commons, Marketing Commons, and the Organizational Behavior and Theory Commons

\section{Recommended Citation}

Reibstein, D. J., \& Farris, P. W. (1995). Market Share and Distribution: A Generalization, a Speculation, and Some Implications. Marketing Science, 14 (3 Supplement), G190-G202. http://dx.doi.org/10.1287/ mksc.14.3.G190

This paper is posted at ScholarlyCommons. https://repository.upenn.edu/marketing_papers/244

For more information, please contact repository@pobox.upenn.edu. 


\title{
Market Share and Distribution: A Generalization, a Speculation, and Some Implications
}

\author{
Abstract \\ In this paper we review evidence of a generalized convex cross-sectional relationship between retail \\ distribution and unit market share, i.e., large-share brands have more share points per percentage of \\ distribution than small-share brands. The dynamics and structure of distribution and share can help \\ explain many phenomena in marketing, including this convex shape: (1) market share is both a cause and \\ an effect of distribution, and (2) in the typical convenience goods distribution system there are a few large \\ outlets that stock many brands and numerous smaller outlets that stock the leading brands only. \\ Generally, the observed cross-sectional "curve" relating distribution and share will reflect the retailers' \\ stocking decisions, not the incremental effect of distribution on share. However, a logically consistent \\ model of share based on (1) and (2), when combined with the assumption of low search loyalty, results in \\ customers being willing to switch from preferred to available brands. A further consequence is that the \\ marginal effect of weighted distribution on share is likely to be increasing, i.e., result in convex curves \\ relating distribution and share for a given brand. In some cases, and for some measures of distribution, \\ these convex curves have been observed in time-series data for brands that failed and lost distribution \\ over a relatively short period of time. The implication is that marketers should monitor distribution \\ carefully, as it is the result of combined effects of brand preference, loyalty, and "push" programs. With a \\ better understanding of the market share/distribution relationship, managers should be in a better \\ position to forecast marketplace results for a given level of distribution.

\section{Keywords} \\ distribution, market share

\section{Disciplines} \\ Business | Business Administration, Management, and Operations | Business Analytics | Business and \\ Corporate Communications | Business Intelligence | Management Sciences and Quantitative Methods | \\ Marketing | Organizational Behavior and Theory
}


Market Share and Distribution:

A Generalization, a Speculation, and Some Implications

by

Professor David J. Reibstein

The Wharton School

The University of Pennisylvania

and

Professor Paul W. Farris

The Darden School

The University of Virginia

April 1994 


\begin{abstract}
In this paper we review evidence of a generalized convex cross-sectional relationship between retail distribution and unit market share, i.e., large share brands have more share points per percentage of distribution than small-share brands. The dynamics and structure of distribution and share can help explain many phenomena in marketing, including this convex shape: (1) market share is both a cause and effect of distribution and (2) in the typical convenience goods distribution system there are a few large outlets that stock many brands and numerous smaller outlets that stock the leading brands only. Generally, the observed cross-sectional "curve" relating distribution and share will reflect the retailers' stocking decisions, not the incremental effect of distribution on share. However, a logically consistent model of share based on (1) and (2), when combined with the assumption of low search loyalty, results in customers being willing to switch from preferred to available brands. A further consequence is that the marginal effect of weighted distribution on share is likely to be increasing, i.e., result in convex curves relating distribution and share for a given brand. In some cases, and for some measures of distribution, these convex curves have been observed in time-series data for brands that failed and lost distribution over a relatively shortperiod of time. The implications is that marketers should monitor distribution carefully, as it is the result of combined effects of brand preference, loyalty, and "push" programs. With a better understanding of the market share/distribution relationship, managers should be in abetter position to forecast marketplace results for a given level of distribution.
\end{abstract}


1. The Generalization: Cross-sectional relationships between brand share and retail distribution show a convex pattern; high-share brands have more share points per point of distribution (e.g., Figure 1). The reasons underlying the shape of this convex curve are the structure of retail distribution for consumer goods (a few large stores, many small ones) and the two-way causality between share and distribution. When search loyalty is low the effect of distribution on share is greatest.

In addition to being valid, a generalization should be interesting and useful. The reader may be motivated to endure our discussion by recalling Frank and Massy's (1965) observation that "It is impossible to predict the effects of a change in manufacturers' promotional strategies upon sales and profits without considering the reaction of retail middlemen." The retail actions which underlie this convex curve may shed light on five other marketing generalizations:

1. small-share brands are in "double jeopardy" of having small penetration rates and lower repeat rates (equivalently, lower loyalty rates or lower shares of requirements). (Ehrenberg, 1988; Fader and Schmittlein, 1993). If small share products are not as widely available repeat purchase rates will be lower (Farley, 1964; Day, 1969; Pessemier, 1982).

2. $\quad$ low advertising elasticities as measured by split-cable systems (Lodish, 1994; Aaker and Carman, 1982; Farris and Reibstein, 1984). One of the functions of advertising is to increases sales (which will further expand distribution) and to increase the confidence of the trade that demand for the product exists. Test procedures which fix distribution may measure short-term effects accurately, but miss long-term effects.

3. asymmetric cross-elasticities, e.g., sales promotions for large brands can gain more sales from small-share brands than vice versa. If large share brands are available in almost all outlets, but small-share brands are in only a subset of stores, it follows that only a portion of the large-share brands' volume is vulnerable to short-term marketing actions by the small-share brands (especially for convenience goods). 
4. customer satisfaction is lower for larger market share brands (Fournell, 1994). If much of the sales volume of large-share brands comes from "compromised choice" (Farris, et al., 1989), on average, the buyers may be less satisfied simply because many did not get their first choice.

5. national advertising is correlated with lower price elasticity while local advertising has the opposite pattern (Kaul and Wittink 1994). This is completely consistent with the observations that more advertising and higher sales lead to wider availability of national brands and more price competition between retailers on those brands. Thus, even while the manufacturer gains monopoly power and can raise prices and margins, the wider availability makes it more of a commodity at the retail level (Steiner, 1978; Farris and Albion, 1982 ).

While we certainly do not claim that these phenomena are totally and completely explained by the fact that distribution is both a cause and a result of unit market share, neither can we rule out that possibility. In each case, the "distribution" explanation seems as strong as others that have been advanced.

In the remainder of this paper we review three measures of retail distribution and describe the evidence for the convex share-distribution relationship. We then turn to a discussion of a logically consistent model of share and distribution for further insights into the question of whether incremental retail distribution yield increasing marginal returns for a given brand in a given marketing situation. A key issue is whether incremental distribution comes from outlets in which there is less within-store competition, i.e., they stock fewer brands within the product category. If brand loyalty is non-existent and the market is of fixed size, obtaining distribution in such stores will guarantee increasing marginal returns to distribution (\% outlets weighted by category volume) by gaining an above average withinstore share of the category. Finally, we discuss the implications for managers and researchers in this area. 


\section{Measures of Retail Distribution and Unit Market Share}

As one reviews the studies that have looked at the distribution-share relationships one can find three principal measures of retail distribution coverage which have been employed. None of the three main measures are as well understood or as straightforward to interpret as we might hope. All three measures require that the same universe of outlets used for measuring the percentage is also used as the basis for defining share. ${ }^{1}$ Each of the three measures may be gross or net of temporary out-of-stocks (OOS). ${ }^{2}$

(1) \% physical distribution (percent of outlets) carrying the product. The major problem with this measure is that it does not distinguish between outlets with high sales/share potential and those with very little. A kiosk is the same as a club store.

(2) \% All Commodity Volume ( \%ACV) is the percentage of total outlet sales in "all commodity groups" made by stores which stock the product in question. In practice, the total sales of the stores in the universe are often estimated on the basis of square feet of selling space, or other indicators. Another problem is that an adjustment is needed to reflect category potential. Per point of $\mathrm{ACV}$, convenience stores represent far more potential for snacks, beverages, and tobacco than they do for cake mixes.

(3) \% Product Category Volume (\%PCV) is the percentage of category sales made by the stores which stock the product in question. In practice, many managers regard \%ACV as if it were exactly the same as \%PCV. In the authors' experience many practicing managers have never considered the distinction. (The PCV measure appears to have been first proposed during work on logically consistent models of share and distribution (Farris, et al. 1989.)

In older data sets, and in instances where distribution data are collected separately from market share, \% physical distribution or \%ACV will be available. ${ }^{3} \% \mathrm{ACV}$ has the greatest information requirements. When \%ACV data are available, managers will often wish to convert it to \% PCV. Information to calculate \%PCV distribution is always available if the same retail sample is used to calculate market share and availability. In practice, we will 
often be forced to calculated \%PCV data from \%ACV by weighting the \%ACV for outlet types by their respective market shares. We conclude that a combination of \%PCV and \%ACV data, matched with market shares calculated from the same retail universe are the preferred variables for marketing managers.

\section{Relevant Theory for the Share-Distribution Relationship}

For a empirical generalization to serve as such, it is necessary for it to be a regular recurring observation, even if the underlying theory is unknown (Bass, 1994). Nevertheless, a theoretical basis for understanding the relationship would improve our ability to anticipate and explain any potential exceptions to the generalization.

\section{Causes}

Distribution causes market share and market share causes distribution. In addition, there are antecedent variables which affect both share and distribution.

1) Distribution leads to market share

Distribution causes market share in that it would be impossible for anyone to buy the product without it being available. For convenience goods, the more available the product the more opportunity the customers have for buying the product. The exception to this would be if there was a high level of brand loyalty in which case, if the product were not available, the customers would refrain from buying until they could find where the product was available. Without loyalty or availability, sales will be lost to the available brands that will benefit from this "compromised" choice. Thus, added distribution provides not only access to the customers which prefer the brand, which would be the linear impact, but also access to the 
other unavailable brands' customers. This is what leads to the accelerated demand illustrated via a convex curve.

Even when loyalty is greater than zero, as the brand is more widely distributed, the inter-store competition for"loyal" customers would intensify. This would often lead to more discounting and in-store promotions of the popular brands. This, in turn, would increase the attractiveness of the widely distributed brands. Both of these potential causes would lead to an increasing market share with every additional level of distribution.

2) Market Share leads to distribution

It is also the case that market share leads to distribution. This is referring to two basic facts: 1) Not all retail outlets are of equal size. As a result, some retailers with considerable shelf space stock a healthy percent of the brands on the market. In these stores, the in-store market share is equal to the pre-store preferences (assuming no differences in displays, store promotions, etc.) 2) There are also stores with limited shelf space. In these stores, the retailer has to decide which brands to carry. It is often the case that the "stocking rule" is to carry the largest share brands (Farris, et al., 1989). For example, one can often witness in convenience stores that only one or two of the most popular brands are stocked. Hence, market share leads to distribution. Based on the arguments above, the available brands will absorb the "compromised" demand.

3) Antecedents which lead to both market share and distribution

If there were any manufacturers' advertising, promotions, or other "pull" items, this' would jointly affect both distribution and market share. Manufacturers' advertising could lead to increased consumer demand and willingness of the retailer to carry the product (Farris and 
Reibstein, 1982; Leone and Schultz, 1978; Montgomery, 1975). Similar arguments could be made for other "pull" items.

Shape of the Relationship

At the outset, we can make two statements about the market share/distribution relationship. First, logic and common sense requires that the "equilibrium" relationship between sales/share and any of the three distribution measures be constrained to pass through the origin. Zero distribution means zero availability and zero sales/share. Zero sales/share will cause retailers to discontinue the brand/product. Second, market share is constrained, by definition, to be less than or equal to \%PCV. Further statements require explicit assumptions about search loyalties, market segmentation by channel type, and retailer behavior with respect to the number of brands they stock. Almost all shapes are theoretically possible under some circumstances, but the convex form is the shape observed most often. The alpha parameter in the simple equation below helps distinguish which shape is observed in practice.

Market share $=\beta \mathrm{ACV}^{\alpha}$

\begin{tabular}{|l|l|l|l||}
\hline $\begin{array}{l}\text { Parameter } \\
\text { Value }\end{array}$ & Linear & Concave & Convex \\
\hline Alpha & $=1.0$ & $0<\alpha<1$ & $>1.0$ \\
\hline
\end{tabular}

a) Linear, intercept zero-- For example if a brand captures an average of twenty-five percent of the sales within stocking stores and has $10 \% \mathrm{PCV}$, the resulting market share would be $2.5 \%$. As distribution increased, to $100 \%$ share would increase to $25 \%$, with the constant assumption of the $25 \%$ within store share. Simulated test market results are often 
linearly scaled down from the $100 \%$ distribution levels used in the test to the presumed level of distribution upon a roll-out.

b) Concave downward, intercept zero- We might observe this pattern if all outlets stocked about the same number of brands, but the manufacturers' distribution policy selected those outlets with greatest potential for that particular brand, i.e., a brand's in-store share would be highest in the "first" stores to be granted distribution. When markets are segmented by outlet type (department store brands of luggage versus discount store brands), this pattern is probably more likely. Other potential causes of a concave pattern might relate to in-store support. More outlets might mean that subsequent outlets, would provide correspondingly less and less support. Also, if there is strong search loyalty to the brand, subsequent outlets would add only non-loyal consumers and marginal returns to distribution coverage would be decreasing. Traditional attraction models would imply a concave relationship.

c) S-shaped, intercept zero--As early as 1965 , Hartung and Fisher proposed an Sshaped relationship. When some proportion of consumers are loyal and the "attractiveness" of a brand is associated with its availability, an S-shape will often result. The combination of in-store support and some loyalty might also result in this shape (Farris, et al. 1989). The parameters of this particular form are not captured in the equation above, although the sshaped is often approximated by either a concave or convex curve for a considerable amount of the data range observed, with the residuals at one extreme to be all of the same sign.

d) Convex outward, intercept zero-- There are two different arguments made for the convex distribution-share relationship. One relates to the stocking decisions of retailers and the "structure" of the retail market. Nuttall (1965) makes a convincing argument that the 
convex relationships described with cross-sectional data reflects the market structure and stocking decisions of retailers. We believe this can be furmly established as a generalization. The second argument relates to time series and the incremental effect of a brand adding distribution coverage. Evidence for the convex effect of distribution in time series is more speculative at this point.

\section{Cross-Sectional versus Time-Series}

While Nuttall (1965) supports the notion of a convex curve on a cross-sectional basis, he also argues that a diminishing effect is likely to be observed for a given brand. ${ }^{4}$ We agree with the former, but believe that his arguments and evidence are weaker for the latter. Nuttall also presents experimental evidence that brands which have distribution coverage "forced" above their "natural" level will see it fall back to the original levels unless extraordinary efforts are made to maintain the new distribution levels. Farris and Reibstein argue that the opposite may also hold: if a brand's share is increased (through advertising, say), then the new level of "natural" distribution will be higher and the addition of this new distribution will bring another increment in share. The process may continue until an equilibrium is reached.

Shown in Figure 2 are the diminishing effects brand specific curves, as implied by Nuttall. These curves capture the distribution effect on market share, if the "better" stores are selected first. The adding of additional stores adds less and less. Also shown in the figure on the left is the retail curve resulting from the "stocking rule." The intersection of these curves, shown on the right-hand side of this figure, illustrates the cross-sectional 
relationship. This illustrates that even if there are brands which have diminishing effects, the observed cross-sectional relationship will remain convex.

Nuttall's Distribution Measures. While Nuttall's work also indicates decreasing marginal returns to distribution for a convenience good (candy), the results are based on \% physical outlets and the dependent variable was sales. For any given brand, adding additional percentage points of physical outlets is likely to be equivalent to adding far less in terms of \%PCV or even \%ACV. Except at the beginning of the life cycle or with radical changes in types of retailer distribution (grocery stores to club stores), the outlet in which a brand is "not yet stocked" are clearly more likely to be the smaller ones that stock fewer brands. This means that we would have to convert Nuttall's \%physical outlets to \%PCV to address the generalization that is most significant to marketers. Very few companies rely on \%physical outlets as the main indicator of distribution intensity. (Although it clearly has value in some cases.)

In addition, analyses of time-series data on share and distribution for a given brand faces some interesting problems. The number of outlets stocking a brand is not likely to change very much over periods of less than one year. However, month-to-month variations in market share can be quite substantial. Many of these variations come from temporary price promotions by the brand and its competitors. Knowledgeable retailers probably will not react to such temporary fluctuations in share (although the beginning and end of the brand's life cycle might be exceptions.) See Table 1 for a list of studies which have investigated the market share/distribution relationship. 


\section{Empirical Evidence}

There are a few studies we could turn to that have previously studied the market share/distribution relation. As referred to earlier, Nuttall was one of the first to investigate the empirical relation. His cross-sectional results for confectioneries show a convex relationship. Results from studies by a) Mercer (1991) for cigarette brands in Scotland and England, b) Farris, et al. (1989) for tortilla chips and instant coffee in the U.S., c) Borin, et al., (1991) with Japanese shampoo data, and d) Verbeke, et al., (1993) with the detergent market in Holland are also shown in Figure 3. All of these studies show the same overall result of a convex curve for different consumer packaged goods in various different contexts/countries.

To further explore this relationship with original data that would allow us to estimate the aforementioned generalizable equation, we turned to the IRI's 1988 Info Supermarket Review. These data included supermarket scanned data--generally frequently purchased consumer packaged goods. For each product category, both market share and the corresponding \%ACV are shown. We randomly selected twelve product categories. These raw data are graphically shown in Figure 4. For all twelve product categories, the least squared estimated exponent, $\alpha$, was significantly, at the $99 \%$ confidence level, greater than one, indicating a convex relationship. The estimated values ranged from 1.80 to 4.68 across the twelve product categories.

There is less evidence available on a time-series basis. The only studies we could find was the study by Verbeke, et al., (1993) which shows the relationship by brand over time, Figure 5a, and the study by Farris, et al. (1989) in Figure 5b. In both of these studies, it 
would appear that the relationship, even on a brand level is convex. While two studies do not allow us to form an empirical generalization on a brand specific level, it certainly leads to speculate the same convex relationship exists.

\section{Implications for Managers and Extensions of This Research}

There are theoretical and immediate managerial benefits to be gained from studying the distribution - share relationship. The theoretical benefits will stem from a more complete model of the markets which incorporate roles for marketers, consumers, retailers, and competitors. It will help us integrate concepts of "pull" (preference and loyalty) and "push" (availability and merchandising effort). Immediate managerial benefits can be gained from learning the "paths" that distribution and share follow in their "natural" equilibrium.

\section{Managerial Implications}

We know that the distribution and share "cause each other." We believe that both effects may be highly non-linear and difficult to estimate. Detailed knowledge of these functions is valuable because this information can help determines the benefits of "buying distribution" through trade promotions, slotting allowances, and other marketing activities. Understanding the structure of the retail market and the "stocking rules" can help marketers determine whether the distribution that has been "bought" can be maintained with the current share and loyalty levels. In markets with low loyalty, incremental distribution as measured by \%PCV can have an increasing effect on share levels. 
Loyalty, as measured by the consumers willingness to search for the brand is a critical factor. Perversely, high loyalty means that retailers will be eager to stock the product, but that the effect of distribution on share will be diminishing.

A better understanding of the overall relationship should give managers a much more realistic picture of what level of both are achievable. It may be quite unlikely to expect a high level of distribution given mediocre market share levels. Further, ones sales forecasting ability should improve, rather than doing a straight linear extrapolation from simulated test markets, for example.

\section{$\underline{\text { Research Implications }}$}

We must study the structure of distribution channels (share and stocking patterns of various outlet types), the shelf management decisions by the trade, and the long-term effects which may be disguised by both the cross-sectional and short-term response elasticities. While one of the basic elements of the marketing mix is distribution, or "place," there is an almost amazing lack of recent research which helps determine what one can do to improve one's level and quality of distribution coverage. Earlier research by Borden (1968), Montgomery (1975), and others focused on obtaining distribution for new products. Most recent academic research to date focuses instead on the question of consumer demand, or how to increase sales once the product is stocked. Category management is an emerging area which will help integrate the ongoing management on "push" and "pull."

As referred to earlier, much of the research investigating the impact of advertising budgets via the use of split-cable systems (Aaker and Carman, 1982; Lodish, 1994) will understate the true impact because they do not allow for the varying levels of distribution that 
would naturally occur and the consequential impact on market share, thereby masking the true advertising elasticity (Farris and Reibstein, 1984.)

As stated at the outset of this paper, there are many marketing phenomena which may have their sources from the underlying market share/distribution relation. More careful consideration needs to be given to this potential underlying cause.

Lastly, it should be pointed out that the generalization which has been shown in this paper has been identified for consumer packaged goods. It is still necessary to explore this relationship to determine its form in other product categories. 
TABLE 1

LITERATURE SUMMARY ON MARKET SHARE/DISTRIBUTION RELATIONSHIP

\begin{tabular}{|c|c|c|c|}
\hline Related Literature & Authors & $\begin{array}{l}\text { Sales/share } \\
\text { Measure }\end{array}$ & $\begin{array}{l}\text { Distribution } \\
\text { Measure }\end{array}$ \\
\hline $\begin{array}{l}\text { Generalization: The cross- } \\
\text { brand/product shape of the } \\
\text { distribution-sales/share } \\
\text { relationship is convex. }\end{array}$ & $\begin{array}{l}\text { Nuttall (1965) } \\
\text { Mercer (1991) } \\
\text { Farris, et al. (1989) } \\
\text { Borin, et al. (1991) } \\
\text { Verbeke, et al. } \\
\text { (1993) }\end{array}$ & $\begin{array}{l}\text { unit sales } \\
\text { unit sales } \\
\text { unit share } \\
\text { unit share } \\
\text { unit share }\end{array}$ & $\begin{array}{l}\text { \% physical } \\
\text { distribution } \\
\% \text { physical } \\
\text { distribution } \\
\text { \%PCV/ACV } \\
\text { \%ACV } \\
\text { \%PCV/ACV }\end{array}$ \\
\hline $\begin{array}{l}\text { Distribution (availability) causes } \\
\text { sales/share }\end{array}$ & $\begin{array}{l}\text { Nuttall (1965) } \\
\text { Farley \& Leavitt } \\
(1968) \\
\text { Leone \& Schultz } \\
(1980) \\
\text { Parsons (1974). }\end{array}$ & unit sales & $\begin{array}{l}\text { \% physical } \\
\text { distribution }\end{array}$ \\
\hline $\begin{array}{l}\text { b. Distribution/store loyalty } \\
\text { increases brand loyalty.* }\end{array}$ & $\begin{array}{l}\text { Jeuland (1979) } \\
\text { Farley (1964) } \\
\text { Day (1969) }\end{array}$ & & \\
\hline $\begin{array}{l}\text { c. Distribution increases } \\
\text { awareness. }\end{array}$ & Heeler (1987) & & \\
\hline Sales/share cause distribution. & Nuttall (1958) & unit sales & \\
\hline $\begin{array}{l}\text { Low sales cause SKU's to } \\
\text { be eliminated }\end{array}$ & Farris, et al., (1989) & unit sales & \\
\hline $\begin{array}{l}\text { For convenience goods (low } \\
\text { search loyalty), the effect of PCV } \\
\text { distribution on share is increasing. }\end{array}$ & Farris, et al., (1989) & $\begin{array}{l}\text { unit share } \\
\text { over time }\end{array}$ & $\begin{array}{l}\text { ACV\% over } \\
\text { time }\end{array}$ \\
\hline
\end{tabular}

*There is an entire literature on consumer reactions to out-of-stocks, which is relevant to the effect of distribution on share and loyalty. Many experiments and surveys have been performed. 
Figure 1

\section{Market Share and Distribution (\% ACV) \\ Convex Relationship \\ (Zero Search Loyalty)}

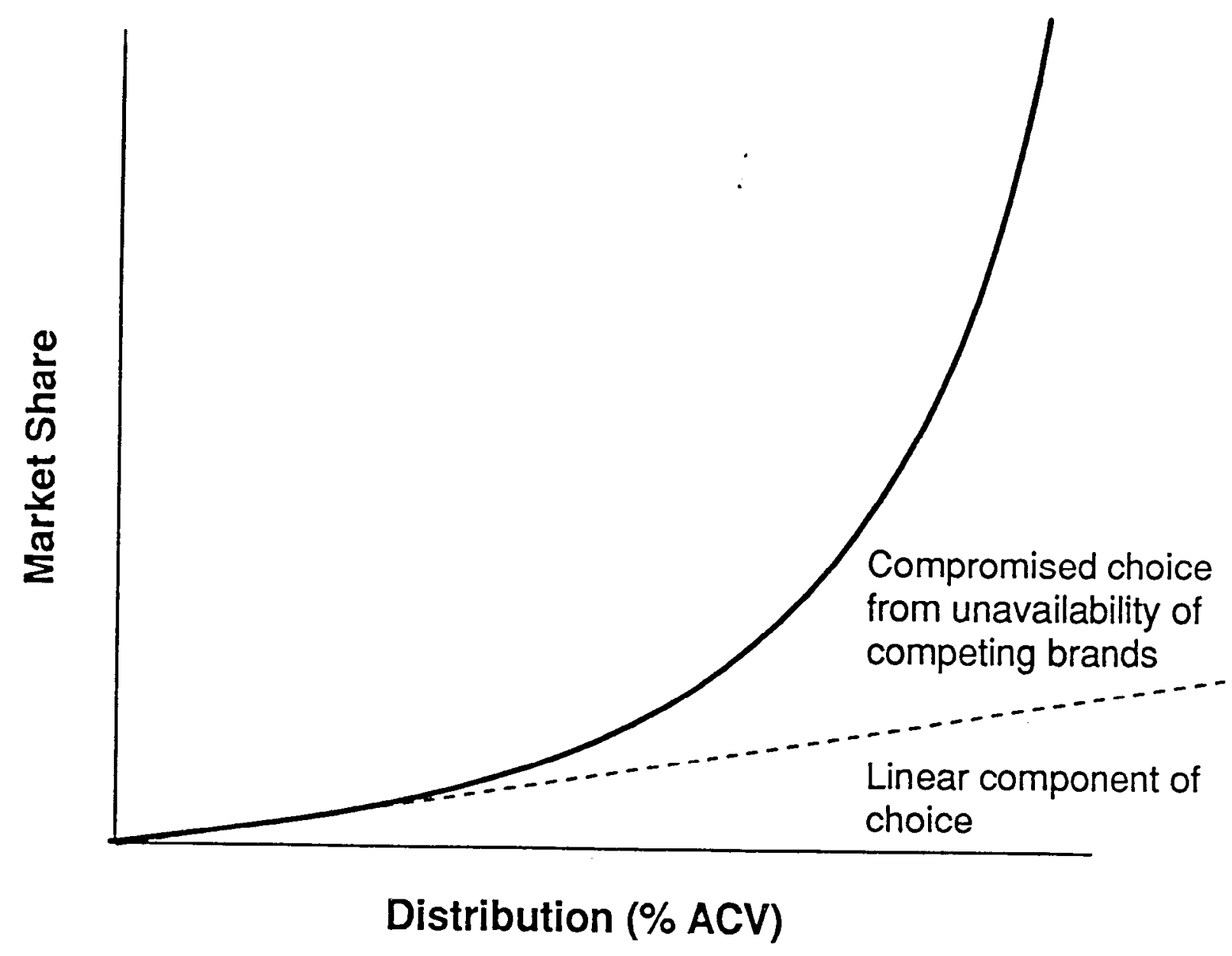




\section{Figure 2}

Hypothetical Time-Series (by brand), \% PCV $\rightarrow$ MS and Retail Stocking Patterns, MS $\rightarrow \%$ PCV

Share and Distribution

Two-Way Causal Relationships

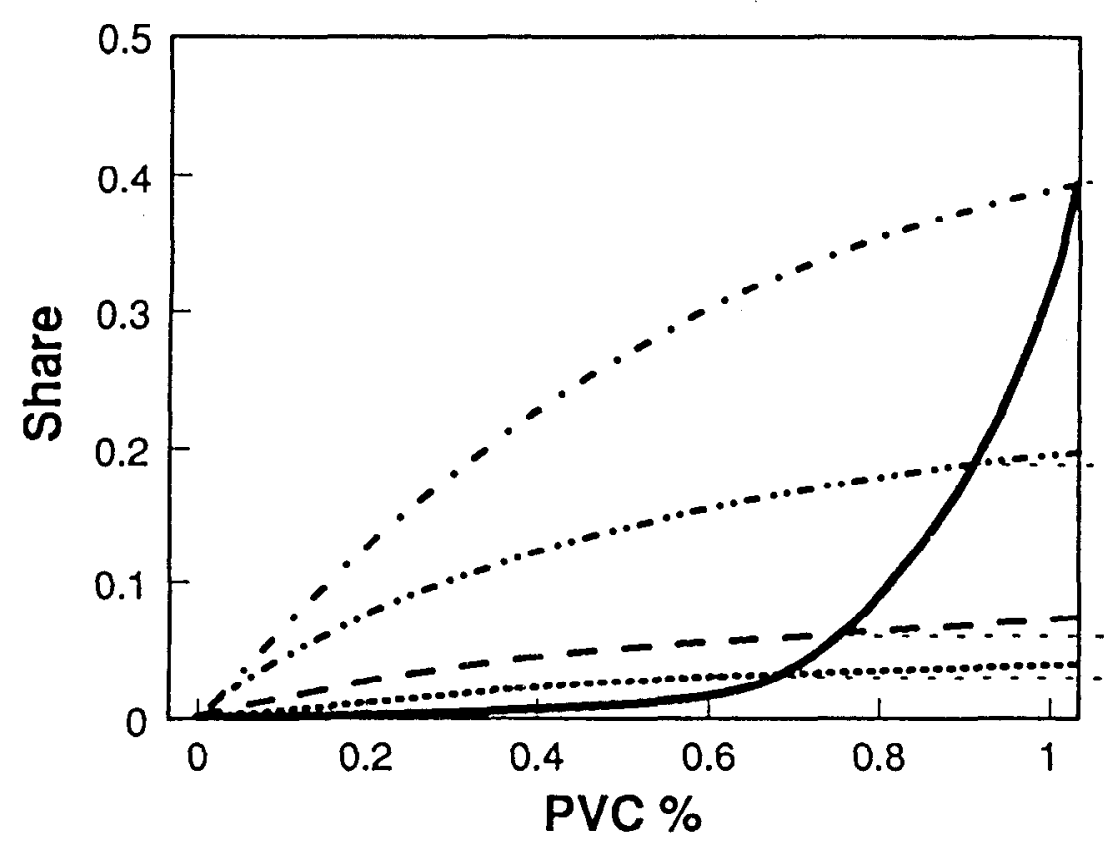

\begin{tabular}{|c|c|c|}
\hline $\mathrm{Re}$ & ailer & MS causes \%PCV \\
\hline $\begin{array}{l}\text { Brand } 1 \\
\text { Brand } 2\end{array}$ & $\begin{array}{l}\text { Brand } 3 \\
\text { Brand } 4 \\
\end{array}$ & $\%$ PCV causes MS \\
\hline
\end{tabular}

Observed Share and PCV

Implied Equilibrium Points

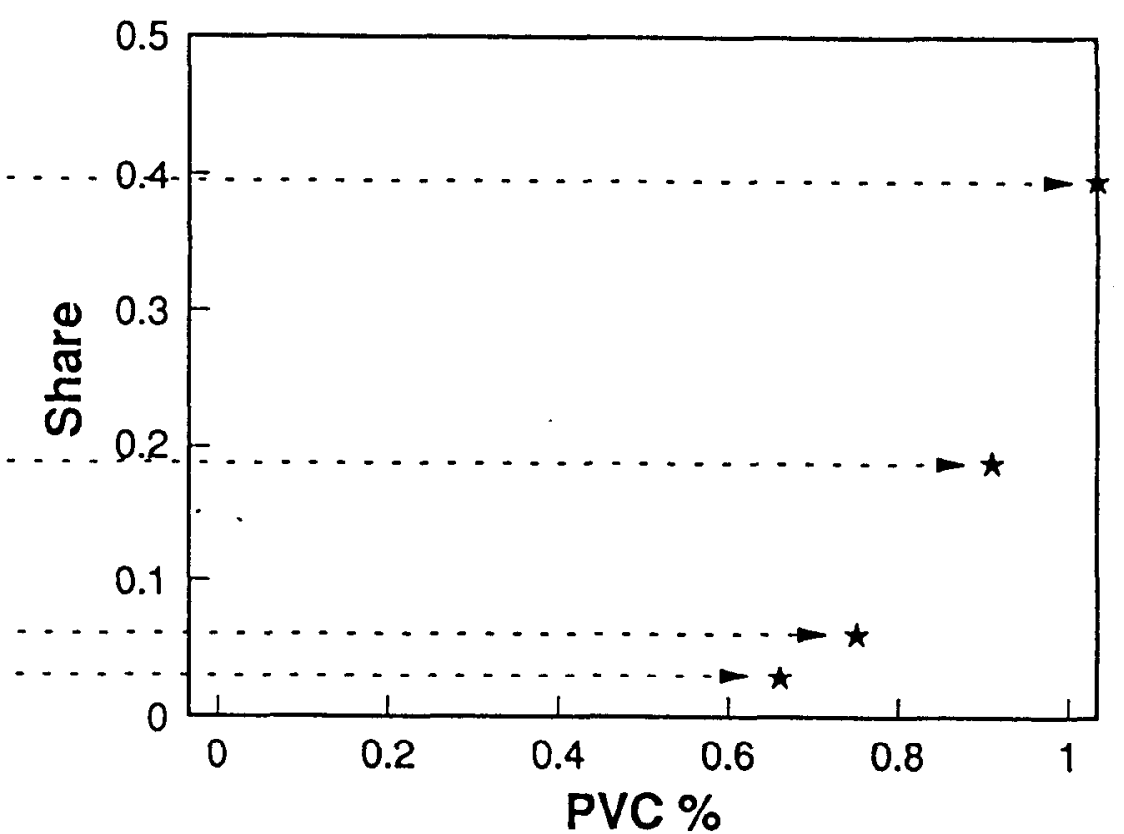

$\star$ Cross-Sectional

Observations 


\section{Figure 3}

\section{Market Share/Distribution Cross-Sectional}

a) Mercer, Sales and Distribution of Gallaher Cigarettes in Scotland

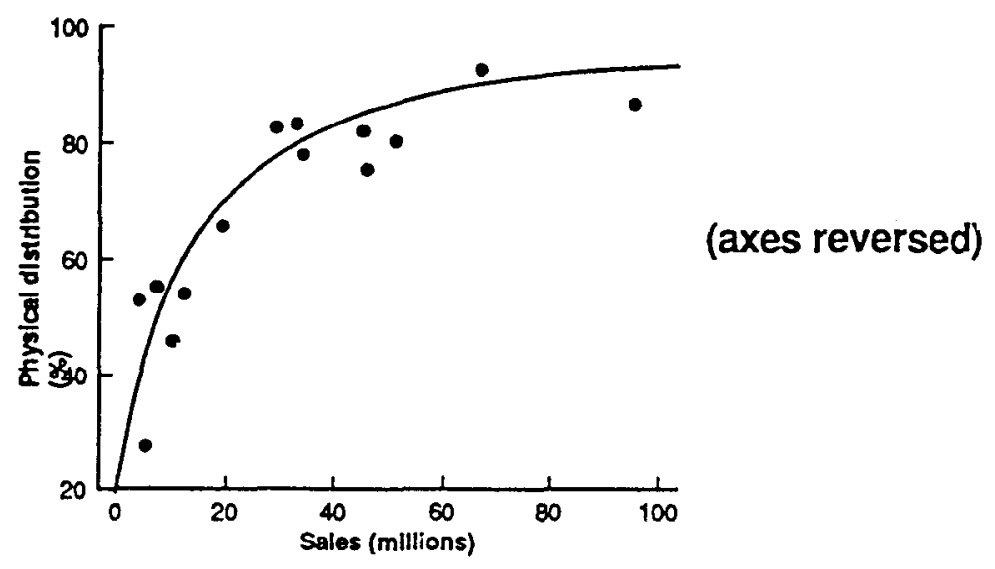

b) Farris et al., Market Share vs. Distribution
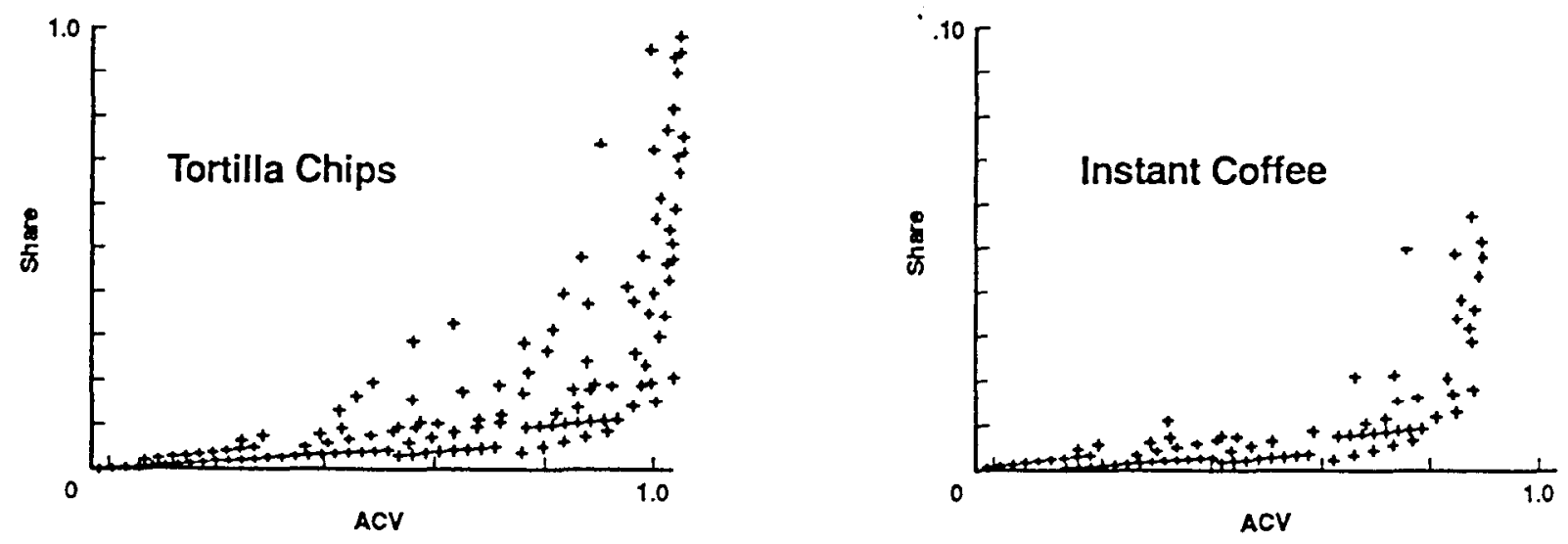

c) Borin, Distribution of Foreign and Domestic Brands

Controlled for Market Share

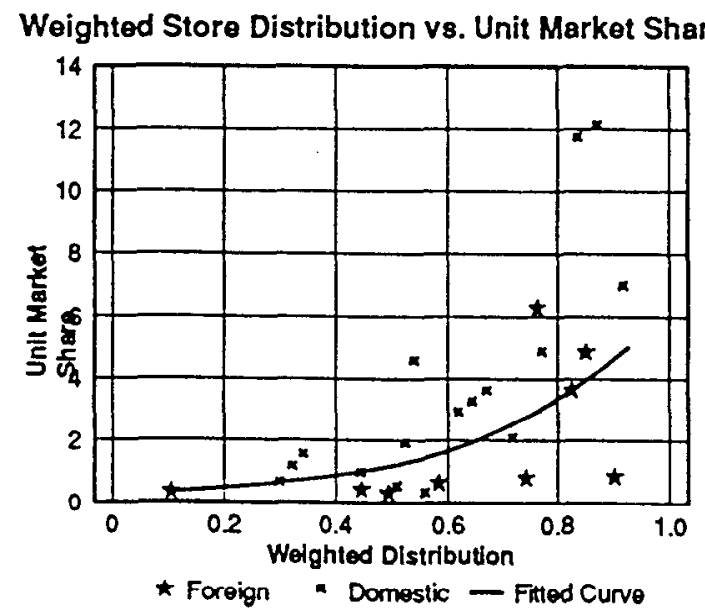

Store distribution weighted by each store's share of all store inventory 
Figure 3 (continued)

Market Share/Distribution Cross-Sectional

d) Verbake et al, Relationships Between Distribution and Market Share for White Detergent Market

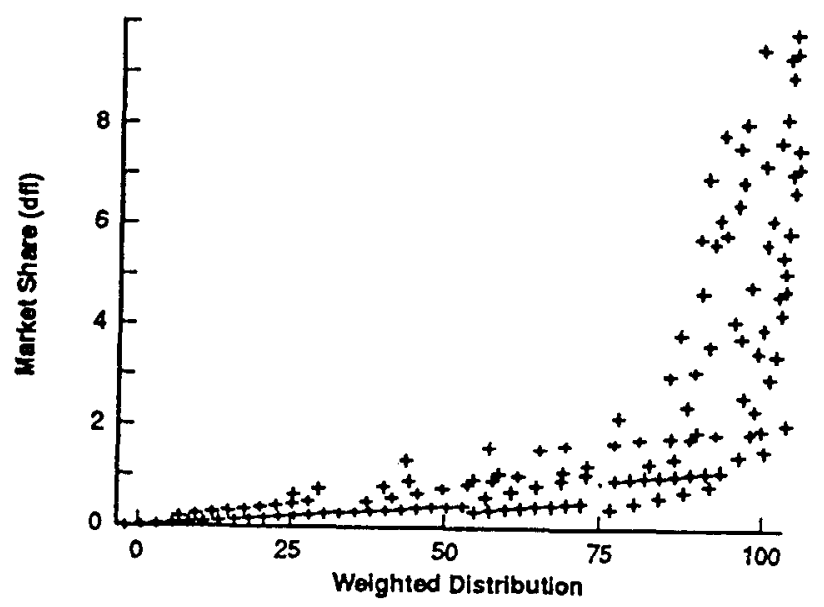



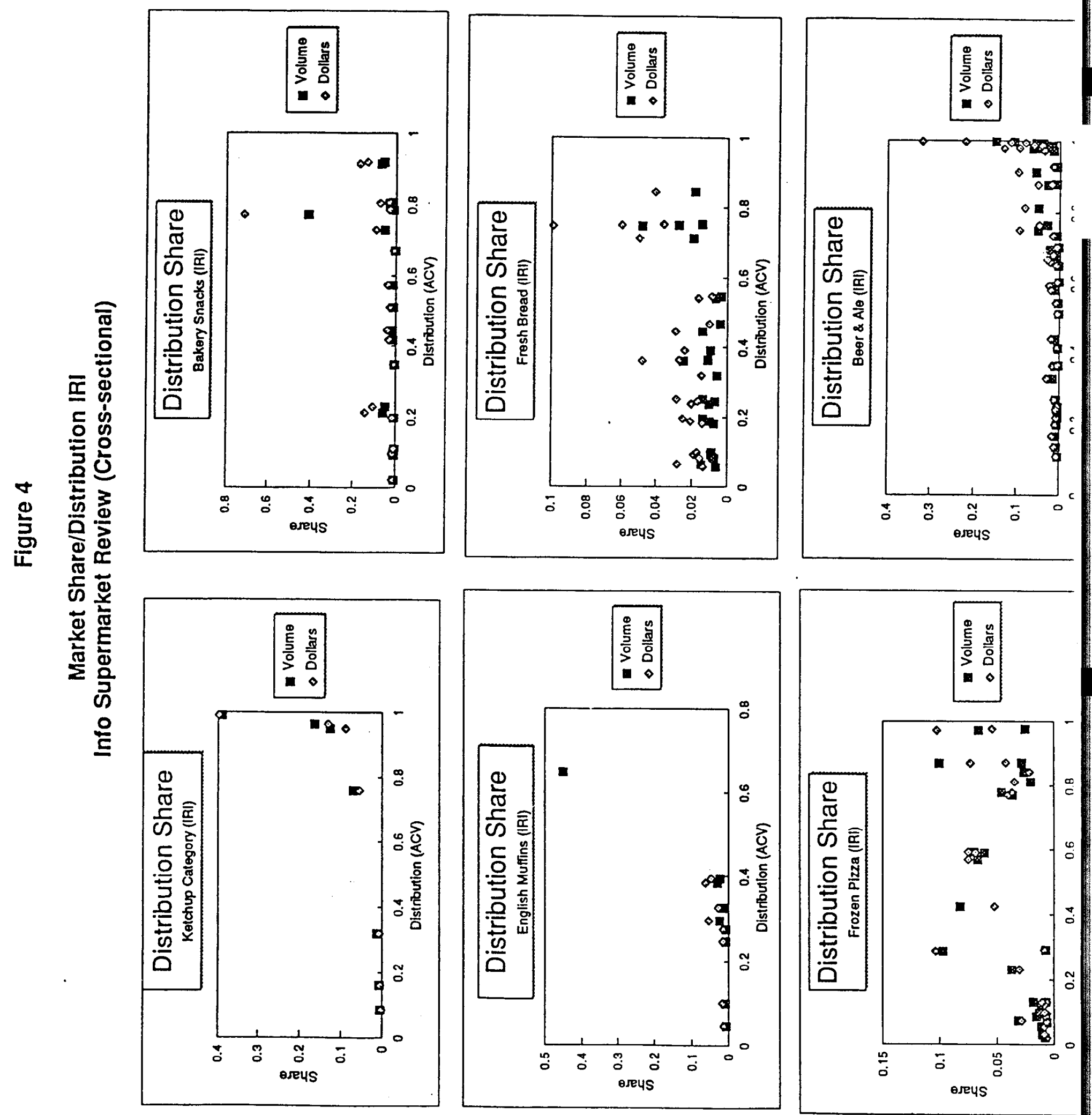

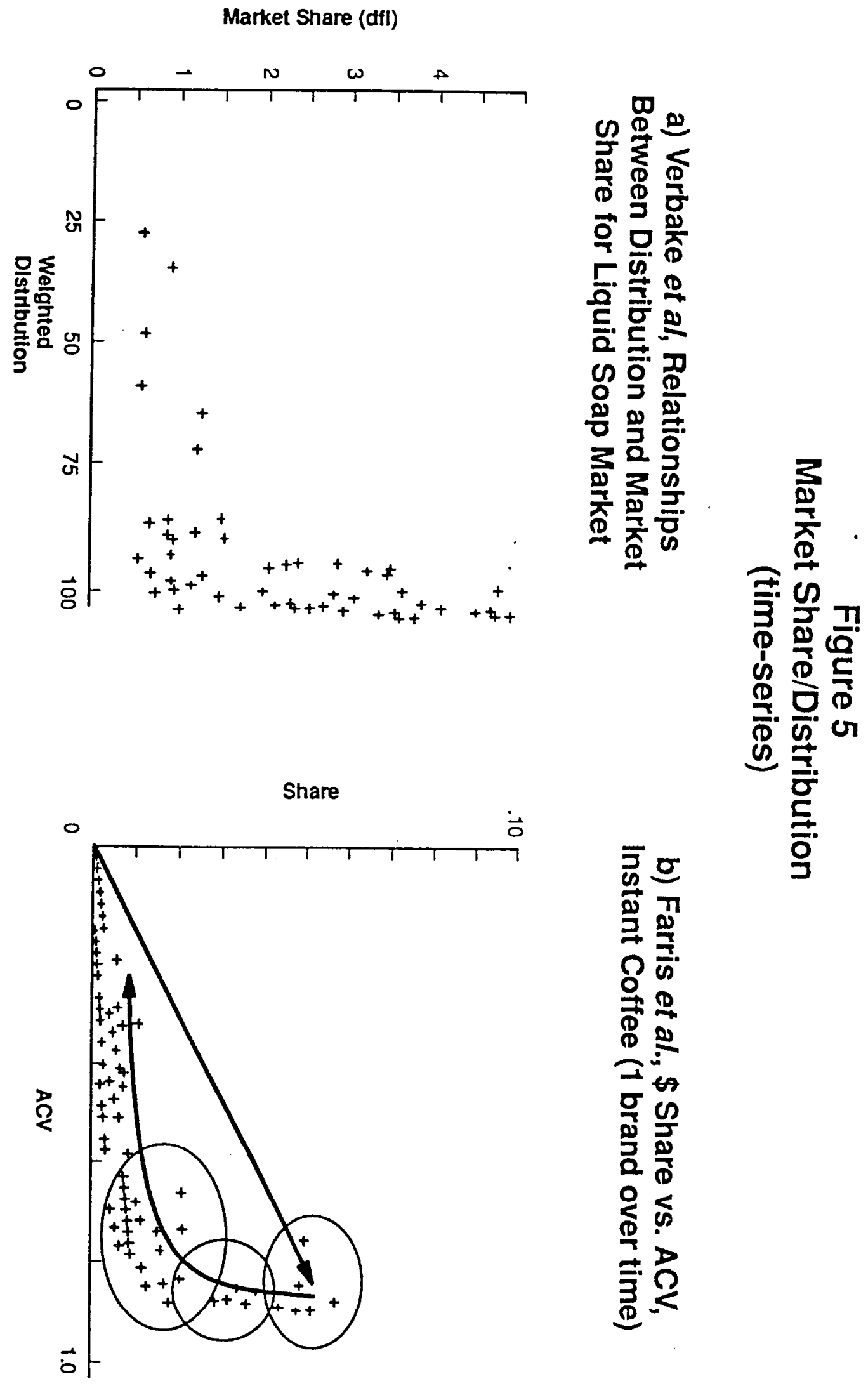


\section{$\underline{\text { References }}$}

Aaker, David A., and James Carman, (1982), "Are you Overadvertising?," Journal of Advertising Research, 22, 4, 57-70.

Bass, Frank M., (1994), "Empirical Generalizations and Marketing Science." Paper presented at the conference on Empirical Generalizations, February 1994, The Wharton School, University of Pennsylvania.

Borden, Neil H. Jr. (1968), Acceptance of New Food Products by Supermarkets, Boston: Division of Research, Harvard Business School.

Borin, Norm, Cynthia Van Vranken, and Paul W. Farris, "A Pilot Test of Discrimination in the Japanese Distribution System," Journal of Retailing, Vol. 6, No. 1, (Spring), 93-106.

Carman, James M. (1970), "Correlates of Brand Loyalty: Some Positive Results," Journal of Marketing Research, 12 (November), 426-31.

Day, George (1969), "A Two-Dimensional Concept of Brand Loyalty," Journal of Advertising Research, 9 (September), 29-35.

Ehrenberg, A.S.C. (1988), Repeat Buying: Facts, Theory, and Applications, London: Charles Griffin and Co.; New York: Oxford University Press.

Fader, Peter S. and David C. Schmittlein (1993), "Excess Behavioral Loyalty for High-Share Brands: Deviations from the Dirichlet Model for Repeat Purchasing," Journal of Marketing Research, Vol. 30, No. 4, (November), 478-93.

Farley, John U. (1964), "Why Does 'Brand Loyalty' Vary Over Products?," Journal of Marketing Research, 1 (November), 9-14.

Farley, John U. and Harold J. Leavitt (1968), "A Model of the Distribution of Branded Personal Products in Jamaica, Journal of Marketing Research, 9 (November), 406-12.

Farris, Paul W. and Mark Albion (1980), "The Impact of Advertising on the Price of Consumer Products," Journal of Marketing, Vol. 44, (Summer), 17-35.

Farris, Paul W. and David J. Reibstein, "Over Control in Advertising Experiments?," Journal of Advertising Research, 24, 3 (June-July), 37-44.

Farris, Paul W., Olver, James and Cornelis de Kluyver, (1989) "The Relationship Between Distribution and Market Share," Marketing Science, Vol. 8, No. 2, pp 107-28. 
Fornell, C., "The Relationship between Distribution (Retail Availability) and Market Share." Paper presented at the conference on Empirical Generalizations, February 1994, The Wharton School, University of Pennsylvania.

Hartung, P. H. and J. C. Fisher (1965), "Brand Switching and Mathematical Programming in Market Expansion," Management Science, Vol. 11, (August), B231-43.

Heeler, Roger M. (1984), "On the Awareness Effects of Mere Distribution," Marketing Science, 273.

Jeuland, Abel P. (1979), "Brand Choice Inertia as One Aspect of the Notion of Brand Loyalty," Management Science, Vol. 25, (July), 671-82.

Leone, Robert P. and Randall L. Schultz (1980), "A Study of Marketing Generalizations," Journal of Marketing, Vol. 44, (Winter), 10-8.

Lodish, Leonard, (1994), "Meta-Analysis of 390 Behavior Scan Real World Ad Experiments." Paper presented at the conference on Empirical Generalizations, February 1994, The Wharton School, University of Pennsylvania.

Mercer, Alan, (1991), Implementable Marketing Research, Prentice Hall.

Montgomery, David B. (1975), "New Product Distribution: Analysis of Supermarket buyer Decisions," Journal of Marketing Research, 12 (August), 225-64.

Nuttall, Colin, (1965), "The Relationship Between Sales and Distribution of Certain Confectionery Lines," Commentary, Vol. 7, No. 4, p 272-85.

Parsons, Leonard (1974), "An Econometric Analysis of Advertising, Retail Availability, and Sales of a New Brand," Management Science, 20 (February), 938-47.

Pessemier, Edgar A. (1982), Product Management, New York: John Wiley and Sons.

Rao, Tanniru R. (1969) "Consumers' Purchase Decision Process: Stochastic Models," Journal of Marketing Research, 6 (August), 321-9.

Steiner, R. (1978), "Marketing Productivity in Consumer Goods Industries--A Vertical Perspective," Journal of Marketing, Vol. 42, (January), 60-70.

Verbeke, Willem, Frank Clement, and Paul W. Farris (1993), "Product Availability and Market Share in an Oligopolistic Market: The Dutch Detergent Market," Darden Working Paper Series. 
$\underline{\text { Notes }}$

1. When supermarkets began to sell perfumes, this presented problems for traditional views of the market.

2. Out-of-stocks have their own measurement issues (e.g., should we "weight" a store which is OOS during peak sales periods, Saturday afternoon for hardware stores, the same as an OOS on Monday morning?).

3. Improved measures of distribution would account for the in-store treatment of the various brands, i.e., the number of facings, the number of shelf-keeping-units, SKU's, displays, prominence of placement, or any other variations which could affect the customers' likelihood of purchasing the brand.

4. We are grateful to Bruce Hardie PHD student for pointing out this reference to us. Nuttall's work anticipated many of our arguments in earlier on the distribution-share relationship. 